\title{
Легированный кремнием GaSb, выращенный методом ГФЭМОC в широком диапазоне соотношений V/III
}

\author{
(C) Р.В. Левин, А.С. Власов, Б.В. Пушный \\ Физико-технический институт им. А.Ф. Иоффре Российской академии наук, \\ 194021 Санкт-Петербург, Россия \\ E-mail: Lev@vpegroup.ioffe.ru
}

Поступила в Редакцию 13 мая 2021 г.

В окончательной редакции 25 мая 2021 г.

Принята к публикации 25 мая 2021 г.

\begin{abstract}
Представлены результаты исследований характеристик эпитаксиальных слоев $\mathrm{GaSb}$, легированных кремнием, выращенных методом газофазной эпитаксии из металлоорганических соединений при соотношении молярных потоков TMSb/TEGa от 1 до 50. Исследованы рентгенодифракционные кривые качания, спектры фотолюминесценции и комбинационного рассеяния света, удельное сопротивление, концентрация и подвижность свободных носителей заряда в слоях $\mathrm{GaSb}: \mathrm{Si}$ в зависимости от соотношения TMSb/TEGa при постоянном молярном потоке $\mathrm{SiH}_{4}$.
\end{abstract}

Ключевые слова: газофазная эпитаксия из металлоорганических соединений, соотношение TMSb/TEGa, эпитаксиальный слой, антимонид галлия, легирование кремнием.

DOI: $10.21883 /$ FTP.2021.10.51447.9678

\section{1. Введение}

Интерес к исследованию GaSb обусловлен тем, что период кристаллической решетки $\mathrm{GaSb}$ соответствует большому количеству многокомпонентных твердых растворов соединений $\mathrm{A}^{\mathrm{III}} \mathrm{B}^{\mathrm{V}}$, величина запрещенной зоны которых варьируется в пределах $0.3-1.58$ эВ. Эти материалы применимы для широкого круга оптоэлектронных приборов в ближней и средней ИК-области спектра (0.8-4.1 мкм), таких как лазеры, светодиоды, фотоприемники и др.

Для изготовления приборных структур необходимо получение слоев как $n$-, так и $p$-типа проводимости. Традиционно для выращивания материала $p$-типа в качестве легирующей примеси используют цинк $(\mathrm{Zn})$, a для материала $n$-типа наиболее распространенной примесью является теллур (Те). Недостатком Zn [1] является высокая скорость диффузии и, как следствие, размытость $p-n$-перехода и сложность легирования тонких нанослоев. Для соединений $\mathrm{A}^{\mathrm{III}} \mathrm{B}^{\mathrm{V}}$ элементы IV группы Периодической системы ( $\mathrm{Si}, \mathrm{Ge})$ являются амфотерными примесями и могут давать $n$-тип или $p$-тип проводимости в зависимости от того, в какую подрешетку они встраиваются. Применение амфотерных $(\mathrm{Si}, \mathrm{Ge})$ примесей для легирования полупроводниковых соединений $\mathrm{A}^{\mathrm{III}} \mathrm{B}^{\mathrm{V}}$ достаточно распространено [2-5]. Si и $\mathrm{Ge}$ проявляли себя преимущественно как донор в $\mathrm{GaAs}$ и как акцептор в $\mathrm{GaSb}$, однако были случаи, когда исследователи наблюдали проявление $\mathrm{Si}$ как акцептор в GaAs. Существуют модели [6,7], которые описывают преимущественное встраивание $\mathrm{Si}$ в металлическую или металлоидную подрешетку, в которых кроме атомарного радиуса атомов подрешетки [6] на преимущественное встраивание $\mathrm{Si}$ также оказывают влияние вакансии [7], вносимые условиями роста (отношение V/III и темпе- ратура). В связи с этим представляет интерес исследование влияния условий роста на процесс встраивания легирующей примеси при эпитаксиальном росте $\mathrm{GaSb}$ c использованием метода газофазной эпитаксии из металлоорганических соединений (ГФЭМОС).

Задачей данной работы было изучение поведения амфотерной примеси на примере кремния при выращивании слоев $\mathrm{GaSb}$ методом ГФЭМОС в широком диапазоне соотношений V/III (1-50).

\section{2. Эксперимент}

Для получения слоев $\mathrm{GaSb}$ применялся метод ГФЭМОС при пониженном давлении. Основные технологические параметры и условия выращивания $\mathrm{GaSb}$ в широком диапазоне соотношений V/III (1-50) приведены в работе [8]. Температура роста составляла $600^{\circ} \mathrm{C}$ при давлении в реакторе 100 мбар, в потоке высокочистого водорода суммарным потоком $5.5 \mathrm{slpm}$. Отличие от описанного [8] режима роста заключалось в добавлении постоянного для всех экспериментов потока силана $\left(\mathrm{SiH}_{4}\right)$ в газовой фазе $\left(2.1 \cdot 10^{-8}\right.$ моль/мин $)$.

В качестве подложек использовали $\mathrm{GaSb}\langle\mathrm{Te}\rangle$ (100) $n$-типа, с концентрацией $n=(3-5) \cdot 10^{17} \mathrm{~cm}^{-3}$, а для измерений концентрации носителей и их подвижности методом Холла слои выращивались на полуизолирующих подложках $\mathrm{GaAs}$ ориентации (100).

При этом время выращивания подбирали таким образом, чтобы толщина эпитаксиальных слоев для всех соотношений была равной $\sim 2$ мкм. Изменение отношения элементов V и III групп в газовой фазе осуществлялось только посредством изменения потока водорода через источник TMSb. 
Сопротивление, концентрация носителей тока и их подвижность измерялись 6-зондовым методом Холла в слоях, при температуре 77 и $300 \mathrm{~K}$ для слоев $\mathrm{GaSb}$, выращенных на полуизолирующих подложках GaAs.

Кристаллическое совершенство слоев оценивалось с помощью рентгенодифракционных исследований на установке рентгеновской дифракции ДРОН-2 (монохроматор $\mathrm{Ge}(001))$, излучение $\mathrm{Cu} K_{\alpha}(0.154$ нм), при размере щелей 1 мм.

Спектры комбинационного рассеяния света (КРС) регистрировались с помощью монохроматора MS5204i, снабженного ПЗС-камерой и решеткой $2400 ш т /$ мм в геометрии обратного рассеяния $z(x y) \bar{z}$. Спектральное разрешение установки было лучше чем $1 \mathrm{~cm}^{-1}$. Мощность лазерного излучения на образце составляла $3 \mathrm{MBT}$ при использовании объектива с 50-кратным увеличением. Умеренный уровень плотности возбуждения исключал локальный нагрев образца и позволял избежать эффекта, при котором концентрация фотовозбужденных носителей достигает существенных значений, способных оказать влияние на форму спектра.

Спектры фотолюминесценции (ФЛ) измерялись при температуре $77 \mathrm{~K}$. Возбуждение проводилось Nd:YAGлазером $(532 \mathrm{Hм}, \mathrm{CW})$ при плотности мощности на поверхности образца $200-300 \mathrm{BT} / \mathrm{cm}^{2}$, излучение детектировалось с помощью $\mathrm{PbS}$ фоторезистора.

\section{3. Результаты и обсуждение}

На рис. 1 представлена зависимость удельного электрического сопротивления от соотношения молярных потоков элементов TMSb/TEGa. Видно, что зависимость имеет выраженный максимум при TMSb/TEGa $=20$, тогда как зависимость для нелегированного GaSb cyщественно отличается и при увеличении соотношения

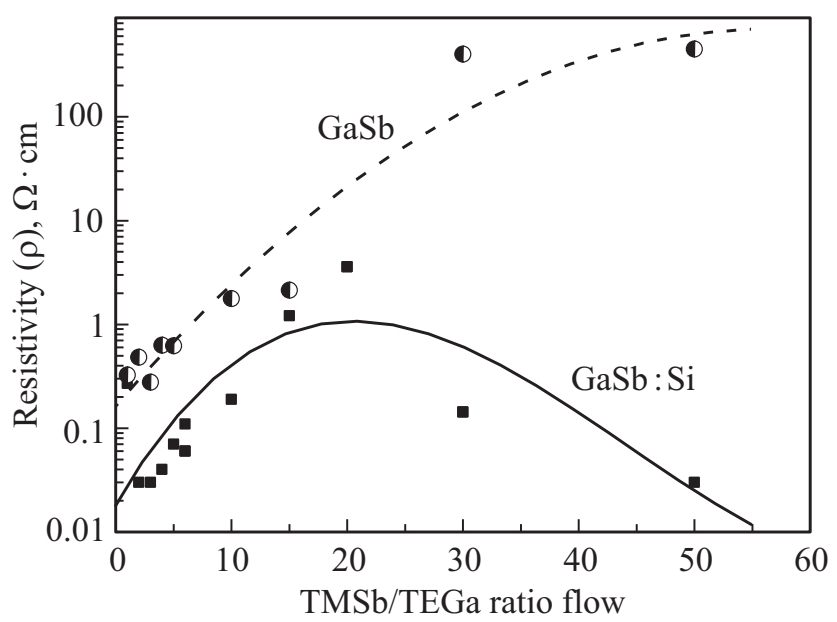

Рис. 1. Зависимость удельного сопротивления в $\mathrm{GaSb}$, легированном кремнием, от соотношения потоков элементов TMSb/TEGa. Для сравнения приведены данные, полученные для нелегированного $\mathrm{GaSb}$.
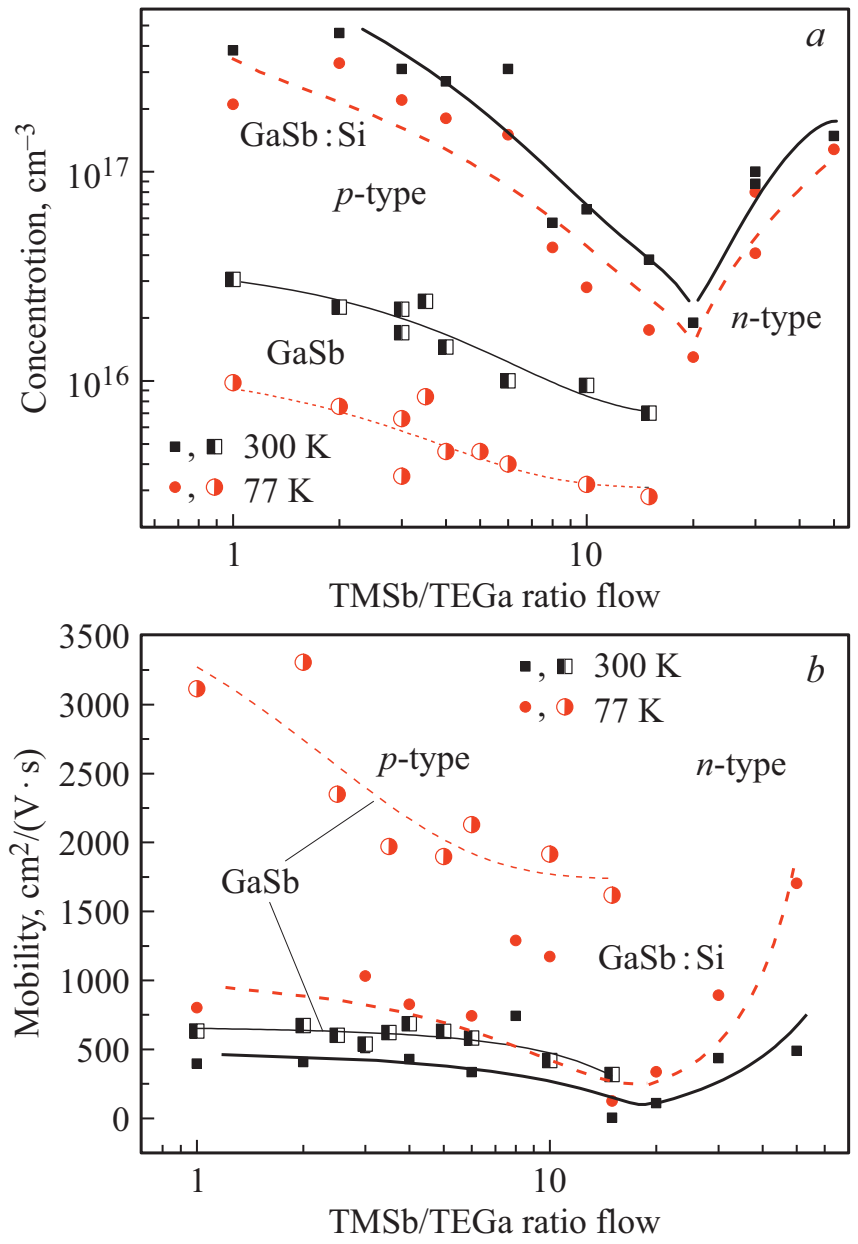

Рис. 2. Зависимость концентрации $(a)$ и подвижности $(b)$ свободных носителей заряда в легированном кремнием $\mathrm{GaSb}$ от отношения потоков элементов TMSb/TEGa. Для сравнения приведены данные, полученные для нелегированного $\mathrm{GaSb}$.

TMSb/TEGa более 20 выходит на „насыщение“ с удельным электрическим сопротивлением $>400$ Ом.см.

По результатам исследования образцов методом Холла было определено, что выращенные эпитаксиальные слои $\mathrm{GaSb}$ (рис. 2,a) в диапазоне соотношений TMSb/TEGa от 1 до 20 имели $p$-тип проводимости. Концентрация дырок снижалась с $4.6 \cdot 10^{17} \mathrm{~cm}^{-3}$ при $\mathrm{V} / \mathrm{III}=2$ с ростом соотношения $\mathrm{TMSb} / \mathrm{TEGa}$ до $2 \cdot 10^{16} \mathrm{~cm}^{-3}$ при TMSb/TEGa $=20$. При дальнейшем увеличении соотношения TMSb/TEGa более 30 наблюдали изменение типа проводимости с дырочного на электронный, при этом концентрация электронов составила $1 \cdot 10^{17} \mathrm{~cm}^{-3}$ при $\mathrm{V} / \mathrm{III}=30$ с незначительным ростом до $1.5 \cdot 10^{17} \mathrm{~cm}^{-3}$ при $\mathrm{TMSb} / \mathrm{TEGa}=50$. Изменение типа проводимости указывает на то, что нами получены условия, при которых кремний преимущественно встраивается в подрешетку сурьмы, активируясь как донор. На рис. 2, a для сравнения добавлены экспериментальные значения нелегированного $\mathrm{GaSb}$, и, как видно из рис. $2, a$, концентрация дырок монотонно убывает при увеличении 
концентрации сурьмы в газовой фазе до соотношения $\mathrm{TMSb} / \mathrm{TEGa}=15$.

На рис. 2, $b$ приведена зависимость подвижности носителей в $\mathrm{GaSb}$, легированном кремнием, от отношения потоков компонентов V и III групп. Подвижность дырок в эпитаксиальных слоях снижалась от $480 \mathrm{~cm}^{2} / \mathrm{Bc}$ при TMSb/TEGa $=2$ до выраженного минимума $<100 \mathrm{~cm}^{2} / \mathrm{Bc}$ при TMSb/TEGa $=15-20$ с дальнейшим ростом до $498 \mathrm{~cm}^{2} / \mathrm{Bc}$ при $\mathrm{TMSb} / \mathrm{TEGa}=50$. На рис. $2, b$ для сравнения добавлены экспериментальные значения нелегированного GaSb, и, как видно, подвижность дырок также снижается в диапазоне соотношений $\mathrm{TMSb} / \mathrm{TEGa}=1-15$.

По результатам анализа рентгенодифракционных исследований была построена зависимость полной ширины на половине высоты (FWHM) рентгенодифракционной кривой качания эпитаксиальных слов $\mathrm{GaSb}$, легированных кремнием, от соотношения молярных потоков $\mathrm{TMSb} / \mathrm{TEGa}$ (рис. 3). FWHM рентгенодифракционной кривой качания подложки без эпитаксиального слоя составляла 44", тогда как FWHM кривых качания для приведенных на рис. 3 слоев $p$-GaSb, выращенных на таких подложках, были в диапазоне 19-42", что указывает на улучшение структуры эпитаксиального слоя по сравнению с подложкой. Зависимость имеет выраженный максимум при соотношении $\mathrm{TMSb} / \mathrm{TEGa}=20$. Наименьшие значения FWHM 18-22" были получены для слоев, выращенных при соотношении молярных потоков TMSb/TEGa в интервале 2-5 и при 40-50.

Спектры КРС слоев, выращенных при соотношениях TMSb/TEGa от 2 до 15, имеют характерный для антимонида галлия $p$-типа проводимости вид (рис. 4, кривая 1) [9]. Единственное изменение, на которое можно обратить внимание, - незначительное сужение полосы от 7 до $5 \mathrm{~cm}^{-1}$ (см. вставку на рис. 4). Наиболее вероятной причиной этого сужения является постепенное

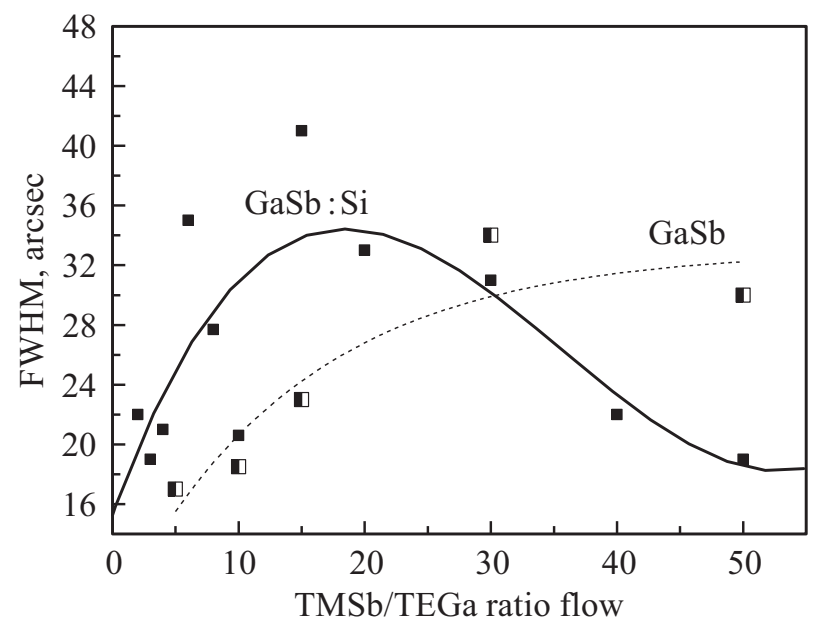

Рис. 3. Зависимость FHWM рентгенодифракционной кривой качания эпитаксиальных слов $\mathrm{GaSb}$, легированных кремнием, от соотношения молярных потоков TMSb/TEGa. Для сравнения приведены данные, полученные для нелегированного GaSb.

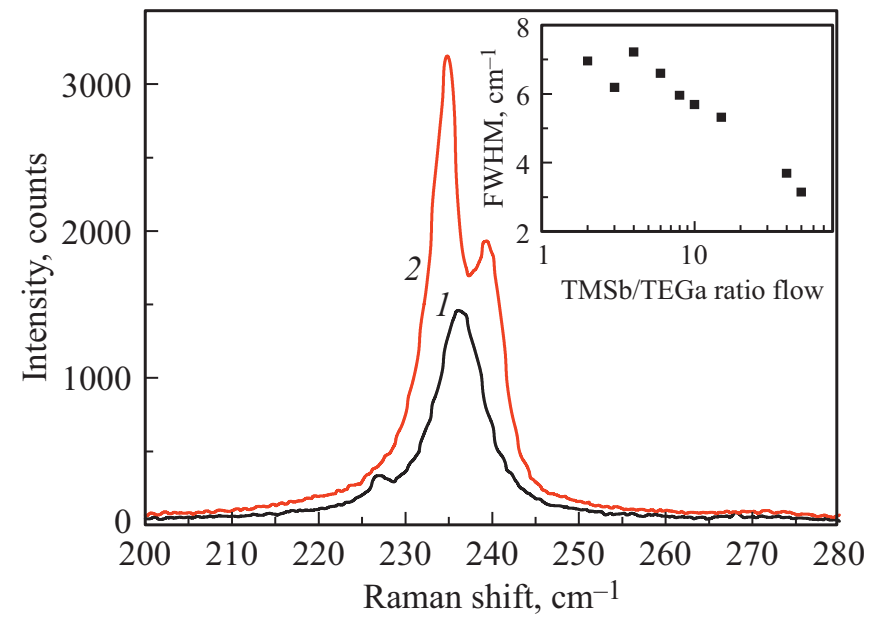

Рис. 4. Спектры КРС эпитаксиальных слоев $\mathrm{GaSb}$, легированных кремнием, выращенных при $\mathrm{TMSb} / \mathrm{TEGa}=2$ (1) и TMSb/TEGa $=20$ (2). На вставке - зависимость FWHM полосы продольного колебания в спектрах рамановского рассеяния слоев $\mathrm{GaSb}$, легированных кремнием, от соотношения молярных потоков TMSb/TEGa.

снижение концентрации свободных носителей (дырок), вызываемое изменением условий роста, что согласуется с данными змерений методом Холла.

При соотношении TMSb/TEGa $=40-50$ спектры существенно сужаются при одновременном увеличении интенсивности, что указывает на изменение типа проводимости и соответствует спектрам рамановского рассеяния $n$-GaSb. При промежуточных значениях $\mathrm{TMSb} / \mathrm{TEGa}=20-30$ поведение спектров становится аномальным. Наблюдается расщепление полосы продольного колебания на две составляющие с повышенной и пониженной частотой колебаний (рис. 4, кривая 2).

На рис. 5 приведено семейство спектров ФЛ эпитаксиальных слоев $\mathrm{GaSb}$, легированных кремнием (поток $\mathrm{SiH}_{4}$ постоянен), от соотношения молярных потоков $\mathrm{TMSb} / \mathrm{TEGa}$.

В спектрах ФЛ слоев можно выделить две основные полосы. Первая полоса $0.793-0.775$ эВ (основной пик) соответствует ширине запрещенной зоны $\left(E_{g}\right) \mathrm{GaSb}$. Небольшой сдвиг полосы относительно значений для нелегированного материала [8] обусловлен наличием хвостов плотности состояний из-за введения легирующей примеси. Тот факт, что при увеличении соотношения V/III увеличивается сдвиг полосы, а также соответственно увеличивается ее FWHM, говорит о том, что кроме изменения концентрации свободных носителей происходит увеличение концентрации собственных дефектов [10]. Вторая полоса (0.730-0.735 эВ) донорноакцепторного типа связана с рекомбинационными переходами через примесные уровни. С увеличением отношения V/III до TMSb/TEGa $=20$ интенсивность ФЛ основного пика снижается при незначительном увеличении FWHM. Интенсивность и положение донорно- 

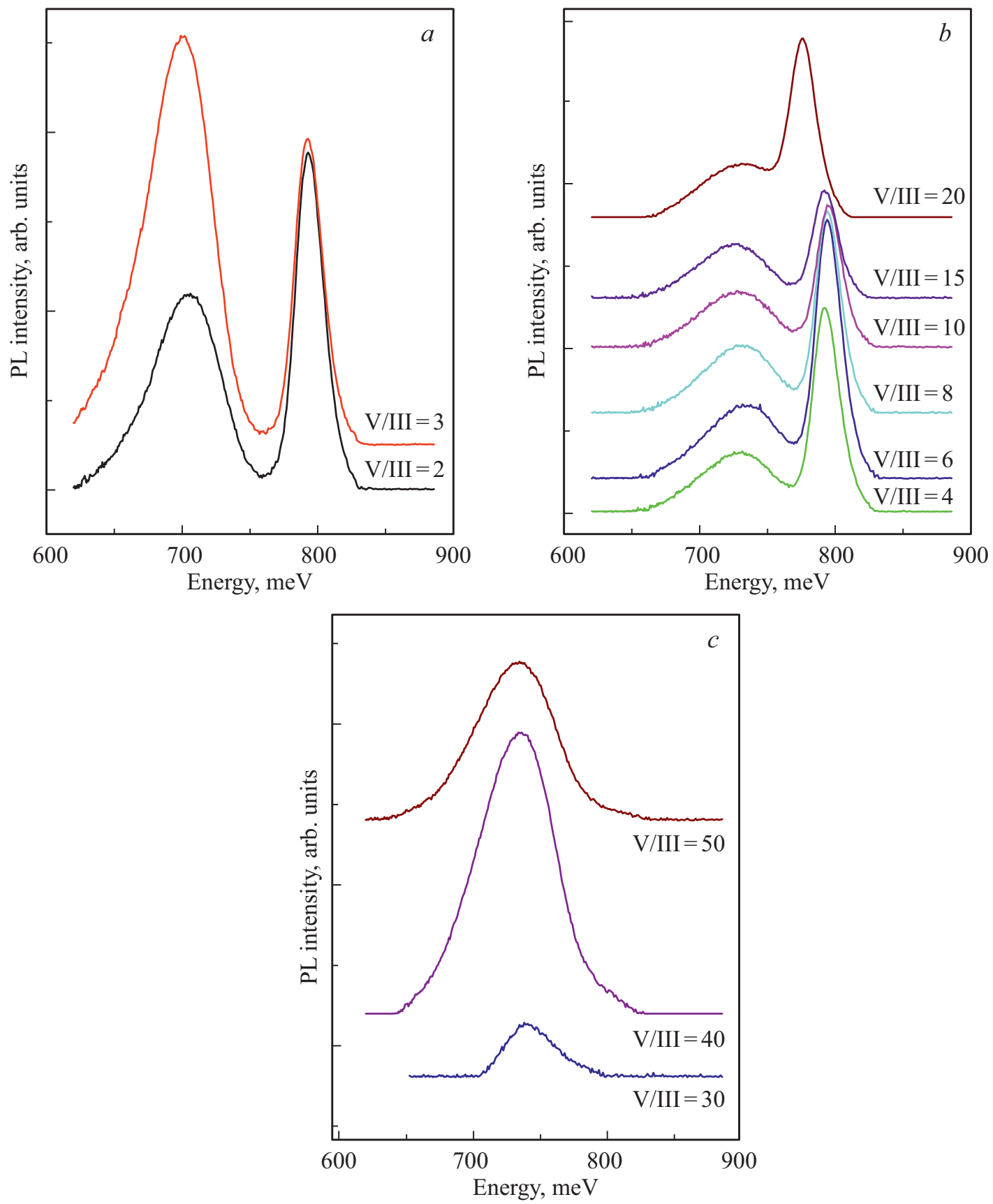

Рис. 5. Семейство спектров фотолюминесценции эпитаксиальных слоев $\mathrm{GaSb}$, легированных кремнием, от соотношения молярных потоков TMSb/TEGa: $a-\mathrm{TMSb} / \mathrm{TEGa}=2-3, b-\mathrm{TMSb} / \mathrm{TEGa}=4-15, c-\mathrm{TMSb} / \mathrm{TEGa}=30-50$.

акцепторного перехода в диапазоне 700-750 мэВ также претерпевает изменения при увеличении V/III: по ее положению спектры можно разделить на три категории $\mathrm{V} / \mathrm{III}=1-2,3-20$ и $30-50$.

Согласно расчетам из первых принципов [11], при малых значениях соотношения $\mathrm{V} / \mathrm{III}=1-2$ (рис. 5, $a$ ) доминирующим типом собственных дефектов в $\mathrm{GaSb}$ является антиструктурный дефект $\mathrm{Ga}_{\mathrm{Sb}}$, выступающий в роли двухзарядного акцептора. В материале $p$-типа проводимости энергетические уровни $\mathrm{Ga}_{\mathrm{Sb}}$ оказываются частично заселены, что приводит к появлению полосы в районе 700 мэВ. При увеличении потока сурьмы V/III > 3 спектр дефектов изменяется и доминирующим типом дефектов должны становиться вакансии галлия $V_{\mathrm{Ga}}$ и метастабильный дефект $\mathrm{Sb}_{\mathrm{Ga}}$, имеющий тенденцию к трансформации $\mathrm{Sb}_{\mathrm{Ga}} \leftrightarrow V_{\mathrm{Ga}}+\mathrm{Sb}_{\mathrm{i}}$. Эти дефекты также имеют характер многозарядных акцепторов, однако можно отметить резкое изменение глубины залегания энергии примеси. Ввиду того что это не может быть связано с резким изменением положения уровня Ферми, можно говорить о существенном изменении в спектре собственных дефектов. Дальнейшее увеличение V/III в 
диапазоне 4-15 (рис. 5,b) сопровождается уширением полосы межзонной рекомбинации и сдвигом всех полос в длинноволновую сторону, что связано с увеличением концентрации собственных дефектов [10]. При соотношении потоков V/III $=20$ (рис. 5,b) в спектре ФЛ присутствуют две полосы с энергиями 776 и 730 мэВ. Подобный аномальный сдвиг полосы на 25 мэВ сопровождается также аномальным поведением в спектрах рамановского рассеяния и может свидетельствовать об образовании некоторой промежуточной фазы. Характерно, что при еще больших значениях V/III $=30-50$ (рис. 5,c) происходит как смена типа проводимости материала, так и спектров ФЛ, которые принимают характерный вид для материала $n$-типа.

\section{4. Заключение}

В результате проведенных исследований показана возможность управления преимущественного встраивания амфотерной примеси Si при выращивании эпитаксиальных слоев $\mathrm{GaSb}$ методом газофазной эпитаксии из металлоорганических соединений в широком диапазоне соотношений V/III.

Исследованы свойства материала таких слоев при разных соотношениях V/III.

Установлено, что при увеличении соотношения V/III сначала плавно, а затем скачком меняется проводимость, что сопровождается увеличением собственных дефектов и изменением их природы.

\section{Конфликт интересов}

Авторы заявляют, что у них нет конфликта интересов.

\section{Список литературы}

[1] Y.K. Su, H. Kuan, P.H. Chang. J. Appl. Phys., 73, 56 (1993).

[2] C. Agert, P.S. Gladkov, A.W. Bett. Semicond. Sci. Technol., 17, 39 (2002).

[3] A.A. Quivy, A.L. Sperandio, E.C.F. Da Silva, J.R. Keite. J. Cryst. Growth, 206, 171 (1999).

[4] B. Lee, S.S. Bose, M.H. Kim, A.D. Reed, G.E. Stillman. J. Cryst. Growth, 96, 27 (1989).

[5] K.F. Longenbach, S. Xin, W.I. Wang. J. Appl. Phys., 69, 3393 (1991).

[6] G. Pindoria, R.A.A. Kubiak, S.M. Newstead, D.P. Woodruff. Surf. Sci., 234, 17 (1990).

[7] A.A. Quivy, A.L. Sperandio, E.C.F. Da Silva, J.R. Keite. J. Cryst. Growth, 206, 171 (1999)

[8] Р.В. Левин, А.С. Власов, А.Н. Смирнов, Б.В. Пушный. ФТП, 53 (12), 1599 (2019).

[9] J.E. Maslar, W.S. Hurst, C.A. Wang. J. Appl. Phys., 103, $013502(2008)$

[10] A.S. Vlasov, E.P. Rakova, V.P. Khvostikov, S.V. Sorokina, V.S. Kalinovsky, M.Z. Shvarts, V.M. Andreev. Solar Energy Mater. Solar Cells., 94, 1113 (2010).

[11] M. Hakala, M.J. Puska, R.M. Nieminen. J. Appl. Phys., 91, 4988 (2002).

Редактор А.Н. Смирнов

\section{Si-doped GaSb grown by MOVPE method in a wide range of $\mathrm{V} / \mathrm{III}$ ratio}

\author{
R.V. Levin, A.S. Vlasov, B.V. Pushnyi
}

loffe Institute, 194021 St. Petersburg, Russia

Abstract Charachterization of Si-doped GaSb epitaxial layers grown by metal organic vapor phase epitaxy is presented. Samples are grown at constant $\mathrm{SiH}_{4}$ flow with a TMSb/TEGa ratio ranged from 1 to 50. $X$-ray diffraction, photoluminescence, Raman scattering, resistivity, free carrier concentration and their mobility are studied. 